\title{
Involvement of calcium signaling in different types of cell death in cancer
}

\author{
Minireview
}

Petr BABULA ${ }^{1}$, Olga KRIZANOVA 2 ,*

${ }^{1}$ Department of Physiology, Faculty of Medicine, Masaryk University, Brno, Czech Republic; 2Institute of Clinical and Translational Research, Biomedical Research Center, Slovak Academy of Sciences, Bratislava, Slovakia

${ }^{*}$ Correspondence: olga.krizanova@savba.sk

Received January 27, 2022 / Accepted February 8, 2022

\begin{abstract}
Programmed cell death is a basic feature of chemotherapeutic (and also radiotherapeutic) intervention. Induction of cell death in tumor cells aims to kill preferentially the tumor cells, with minimal impact on the normal cells. Although apoptosis is the most obvious type of cell death induced by chemotherapeutics, several other types can also be activated, especially in conditions, where cells are resistant to apoptosis induction. Calcium signaling was shown to play an indisputable role in the activation of different types of cell death. Local increase of the calcium in time and precise place of this increase is secured by calcium transport systems. In this review, we summarized the involvement of some calcium transport systems in apoptosis, autophagy, necroptosis, ferroptosis, and mitophagy during cancer development and treatment.
\end{abstract}

Key words: calcium transport systems; cell death; cancer

Cell death, a group of processes leading to the elimination of unwanted cells in the organism, is extremely important for human health. Malfunctioning of these processes can result in cell accumulation with serious consequences. Cells that are not able to promote autosuicide may accumulate further genetic damage that advances neoplastic transformation (for review see [1]). Different types of cell death play a crucial role in cancer development, progression, but also in treatment. Initially, one type of cell death-necrosis was largely reported in the hypoxic areas in growing tumors [2]. Nowadays, a huge amount of information about cell death involves also cancer therapy associated with killing malignant cells with a minimal impact on normal cells.

Although the most common and also best-described cell death in cancer is apoptosis and necrosis, other types like autophagy, ferroptosis, necroptosis, pyroptosis, etc. boosted a perspective of their utilization in cancer treatment, since most tumors harbor the innate resistance to apoptosis. Apoptosis is the most common non-inflammatory programmed cell death and is characterized by membrane blebbing, apoptotic body formation, DNA fragmentation, and chromatin condensation [3]. Necrosis is considered to be an uncontrolled cell death that results in the disruption of membrane integrity and causes an inflammatory response [4]. Necroptosis is a programmed version of necrosis [5]. Autophagy, as another programmed cell death, is an evolutionarily conserved degradation pathway, where over 40 autophagy-related genes/proteins are involved [6]. Ferroptosis is an iron- and lipotoxicity-dependent form of programmed cell death [7]. Pyroptosis, an inflammatory form of cell death, is triggered by certain inflammasomes, leading to activation of inactive cytokines like IL-18 and IL-1 $\beta$ [8]. All these processes target different pathways and the only common denominator is the death of the cell. Under special circumstances, more than one type of cell death can be induced.

Calcium signaling has been reported to affect cell death through different calcium transport systems [9]. Intracellular calcium significantly influences the proliferationapoptosis balance [10]. Calcium is the most variable second messenger involved in a variety of intracellular and extracellular cascades, thus targeting a huge number of physiological processes. In addition, it plays an essential role in cell life and death decisions. Calcium signaling is deeply involved not only in the initiation and progression of cancer but also in the induction cell death of cancer cells. Calcium signaling is realized through the rapid local increase of calcium in a 
certain time and place (for review see [11, 12]). Calcium transport systems are deeply involved in the changes of intracellular calcium concentration, either transient or sustained. Several calcium transport systems localized on the plasma membrane, or on the membranes of intracellular organelles are responsible for a fine-tuning of intracellular calcium concentration (Figure 1). Overexpression and/or activation of different calcium transport systems in cancer decide about the fate of a cell. For example in hypoxic tumors, the sodium/ calcium exchanger that is localized on the plasma membrane, started to work in a reverse mode and participated against intracellular acidification by forming a complex with sodium/ proton exchanger and eliminating the excess of intracellular sodium ions [13]. On the other side, inositol 1,4,5-trisphosphate $\left(\mathrm{IP}_{3}\right)$ receptors of type $1\left(\mathrm{IP}_{3} \mathrm{R} 1\right)[14,15]$ and type 2 [16] were shown to participate in the induction of apoptosis. Also, during tumorigenesis and blastic transformation type 3 sarco/endoplasmic ATPase (SERCA 3) expression was decreased [17], whereas in PC12 cells, SERCA3 was involved in the diterpenoid triptolide-induced apoptosis [18]. Tumorigenesis probably involves the altered expression of one or more transient receptor potential (TRP) proteins, depending on the nature of cancer. The unambiguous changes are those involving TRPM8, TRPV6, and TRPM1 [19]. This review provides the current knowledge about the involvement of calcium transport systems in different types of cell death, mainly in apoptosis, autophagy, necroptosis, mitophagy, and ferroptosis.

\section{Apoptosis and regulation by calcium transporters}

Apoptosis is the most widespread and best-characterized type of cell death. This type of cell death is under precise control, and it is typically manifested by translocation of phosphatidylserine from inner to outer phospholipid layer, dysfunction of mitochondria, chromatin condensation, DNA and nuclear fragmentation, activation of different caspases, and membrane blebbing [20]. Two types of pathways were described to be activated in apoptosis - mitochondrial intrinsic and outer extrinsic pathway [21]. Although both these mechanisms are completely different, the final outcome results in the activation of executive proteases of apoptosis

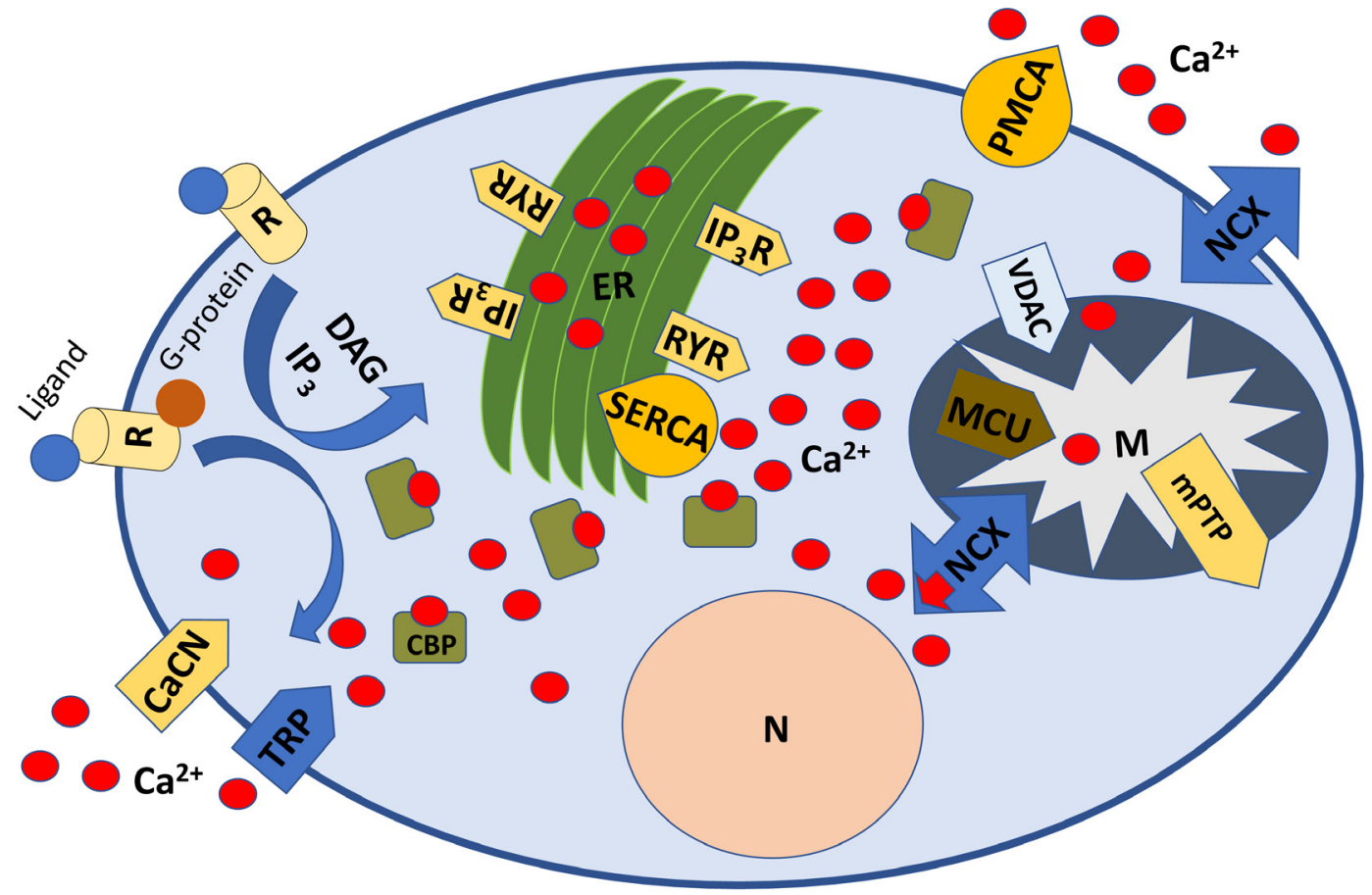

Figure 1. Calcium transport systems are localized on the plasma membrane and also on the intracellular structures. Calcium ions enter the cell through different types of calcium channels $(\mathrm{CaCN})$ and also through the sodium/calcium exchanger (NCX). The special type of calcium channel is the transient receptor potential (TRP) channel. The activity/state of these two calcium transport systems may be influenced by G-proteins coupled with various types of receptors $(\mathrm{R})$. The release of calcium ions from the cell is realized through plasma membrane calcium ATPase (PMCA). Calcium can be also released from the intracellular stores (e.g., endoplasmic reticulum; ER) as a part of cell signaling (inositol 1,4,5-trisphosphate-IP ${ }_{3}$, and diacyl glycerol-DAG as second messengers) by ryanodine receptors (RyR) and inositol 1,4,5-trisphosphate receptors (IP $\left.{ }_{3} \mathrm{R}\right)$. ER can be loaded by calcium through sarco/ endoplasmic reticulum ATPase (SERCA). The variety of isoforms of these transporters was described up to now responsible for different physiological/ pathophysiological processes. Mitochondrial calcium transport systems are also involved in calcium signaling-mitochondrial NCX, mPTP, and mitochondrial uniporter (MCU). In cell signaling, local concentrations of calcium ions are crucial to control signaling pathways. Calcium-binding proteins are involved in the regulation of local concentrations of calcium ions. Abbreviations: N-nucleus, M-mitochondrion, CBP-calcium binding protein, VDAC-voltage-dependent anion channel, mPTP-mitochondrial permeability transition pore 
- caspase-3, -6, or -7. Caspases are crucial enzymes in the mechanism of apoptosis since besides their executive function represented by protease cleaving activity, they are also responsible for the initiation of apoptosis (caspase-2, $-8,-9$, and -10) [22]. The extrinsic pathway is activated upon binding proper ligands to cell death receptors, while the intrinsic (mitochondrial) pathway is activated by excess of calcium ions, irreparable genetic damage, hypoxia, severe oxidative stress, etc. [23]. The importance of $\mathrm{Ca}^{2+}$ signals in the regulation of apoptosis (Figure 2) was described by Pinton et al., who have shown that calcium transfer from the endoplasmic reticulum to mitochondria is crucial for the initiation of programmed cell death by some apoptotic stimuli [24]. The important type of calcium release channel localized on the endoplasmic reticulum and involved in apoptosis is the inositol 1,4,5-trisphosphate $\left(\mathrm{IP}_{3}\right)$ receptor $\left(\mathrm{IP}_{3} \mathrm{R}\right)$ [14]. These receptors form a calcium channel, which upon activation by $\mathrm{IP}_{3}$ and calcium is able to release calcium to the close vicinity of mitochondria. Three types of $\mathrm{IP}_{3} \mathrm{Rs}$ were cloned and characterized up to now. The $\mathrm{IP}_{3} \mathrm{R} 1[15$, $25]$ and $I_{3} R 2[26,27]$ were shown to have the proapoptotic effect, while $\mathrm{IP}_{3} \mathrm{R} 3$ revealed opposite, anti-apoptotic effect $[28,29]$.

In addition, another group of calcium transport systems localized on the endoplasmic reticulum affects apoptosis induction. Truncated sarco/endoplasmic reticulum ATPase (SERCA) type 1 that is not able to pump calcium into the endoplasmic reticulum was able to significantly induce apoptosis in liver cells [30]. Another type of SERCA SERCA3 expression was selectively induced during differentiation, whereas during tumorigenesis and blastic transformation SERCA3 expression is decreased [17]. We have shown that the blocking of SERCA3 prevented the increase in apoptosis due to diterpenoid triptolide treatment. A decrease in the ATP production by a replacement of glucose in the cultivation medium for its non-utilizable analog 2-deoxyglucose also prevented the induction of apoptosis in the triptolide-treated PC12 cells, thus suggesting the role of SERCA3 in triptolide-induced apoptosis in PC12 cells [18].

Although it is evident that a variety of calcium transport systems localized mainly on the endoplasmic reticulum is involved in the modulation of apoptosis, the modulation of calcium transport systems localized on the plasma membrane of cancer cells is not so widely documented. One of the reasons could be that these channels are opened when intracellular calcium stores are depleted. Depletion of the endoplasmic reticulum activates stromal interaction molecule 1 (STIM1) which functions as a calcium sensor and results in the opening of some transient potential (TRP) channels. One of these channels is a transient receptor potential vanilloid 1 (TRPV1) channel, which modifies the balance between apoptotic and proliferative signaling pathways [10]. In gastrointestinal cancer, other types of TRP channels (TRPM2, TRPM6, TRPM7, and TRPM8) are implicated [31]. STIM1 can activate another store-operated calcium channel - ORAI1 - that can contribute to calcium overload, with pro-apoptotic consequences [32].

\section{Autophagy and regulation by calcium transporters}

Autophagy is a self-digesting mechanism responsible for the removal of long-lived proteins, damaged organelles, and malformed proteins during biosynthesis by lysosomes [33]. The process of autophagy is initiated by two proteins, the UNC51-like kinase 1 (ULK1) complex and the Bcl-2interacting myosin-like coiled-coil protein (Beclin 1) [34]. Stress conditions regulate activities of protein kinases mammalian target of rapamycin (mTOR) and 5' adenosine monophosphate-activated protein kinase (AMPK). These kinases regulate the phosphorylation of ULK1 and its activation. The direct connection between stress condition and the activation of ULK1 is well documented. Stress conditions include for example starvation. Ikari et al. have shown that starvation increases the intracellular concentration of $\mathrm{Ca}^{2+}$ from the endoplasmic reticulum (ER) via $\mathrm{IP}_{3} \mathrm{Rs}$ and from lysosomes [35]. The $\mathrm{IP}_{3} \mathrm{R}$ modulates a diverse range of cellular functions, including autophagy (Figure 2). Inhibition of $\mathrm{IP}_{3} \mathrm{R}$ with a specific antagonist as well as the use of its knockout via small interfering RNAs stimulates autophagy. In accordance, upregulated $\mathrm{IP}_{3} \mathrm{R}$ with elevated $\mathrm{Ca}^{2+}$ levels and calcium signaling inhibits autophagy [36]. The unfolded protein response (UPR) is a process involved in the sensing of ER stress and is involved in the upregulation of autophagy components resulting in the removal of misfolded proteins $[37,38]$. UPR is associated with changes in the expression of proteins involved in cellular calcium handling (e.g., $\mathrm{IP}_{3} \mathrm{R}$ and GRP78/BiP); in addition, proteins involved in UPR regulate SERCA activity through indirect control of calnexin/ calcineurin phosphorylation. $\mathrm{Ca}^{2+}$ binds to calcineurin, which dephosphorylates the forkhead transcription factors (FOXOs). FOXOs are involved in metabolism and autophagy and play a crucial role in a number of both physiological and pathological processes, e.g., cancer [39]. FOXOs have been implicated in autophagy in a variety of cell types and induce the expression of a number of autophagy genes involved in various stages of the process, including LC3b, Gabarapl1, Pi3kIII, Ulk2, Atg12l, Beclin 1, Atg4b, and Bnip3 [39, 40].

In the next step of autophagy, active ULK1 phosphorylates and activates Beclin 1. The importance of $\mathrm{Ca}^{2+}$ in the cytoplasm must be mentioned here. Calcium/calmodulindependent protein kinases (CaMKs) are key regulators of calcium signaling [41]. Calcium/calmodulin-dependent protein kinase II (CaMKII) is a serine/threonine protein kinase that is a member of the CaMK family and affects the phosphorylation of Beclin 1 to promote K63-linked ubiquitination of Beclin 1 and activation of autophagy [42]. Active ULK and Beclin 1 complexes re-localize to the site of initiation of autophagosome and they contribute to downstream machinery of autophagy - generation of phosphatidylinositol 3-phosphate (PI3P) from phosphatidylinositol at the 


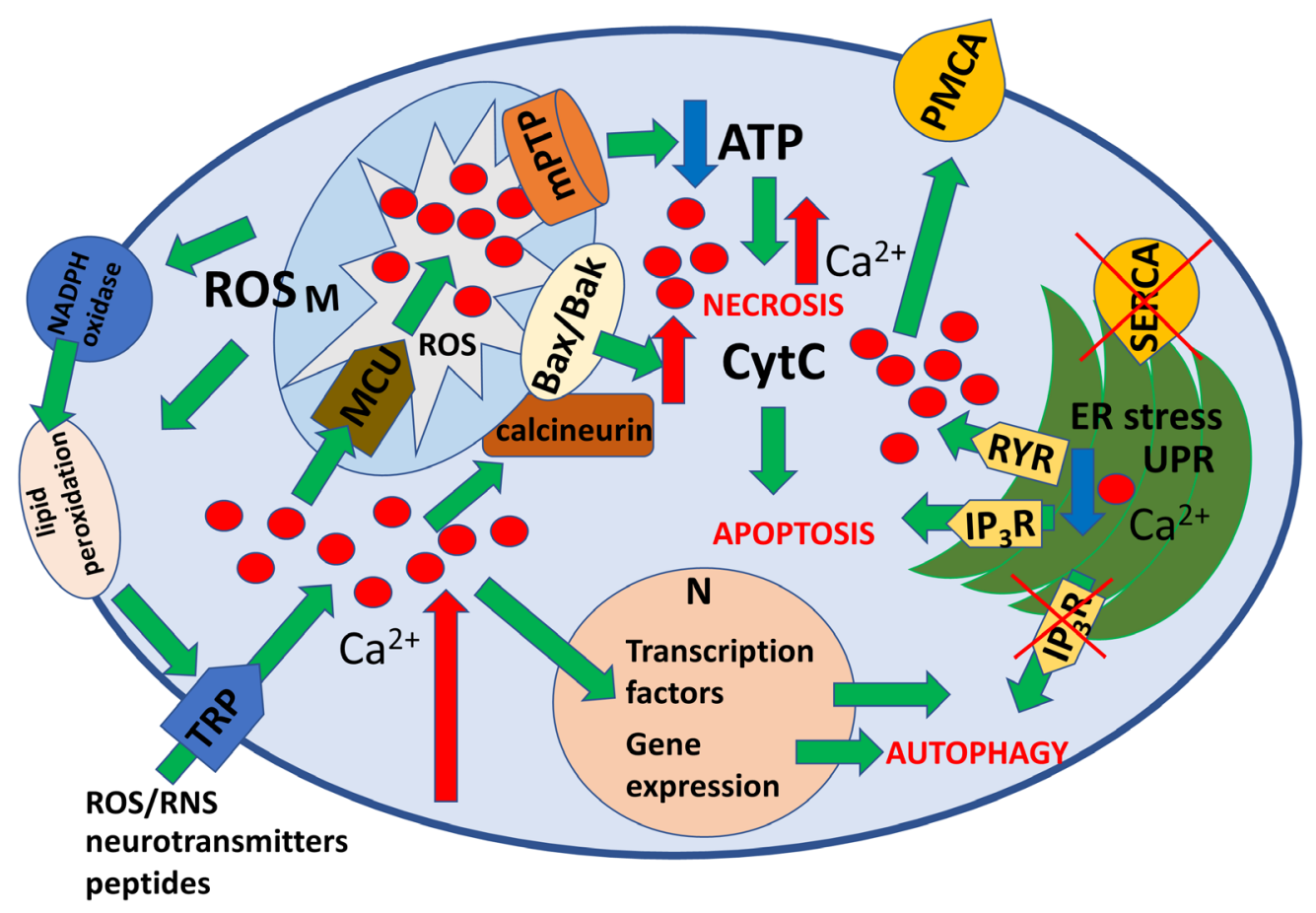

Figure 2. Intracellular calcium ions and cell deaths. An increase in the intracellular calcium concentration due to various stimuli (e.g., stress, increase of amounts of reactive oxygen species (ROS), presence of some neurotransmitters, or peptides) is mediated from the extracellular sources via transient receptor potential (TRP) channel, or from intracellular stores (endoplasmic reticulum and mitochondria, respectively). The release of calcium ions from ER via $I P_{3} R$ and $R Y R$ is closely associated with unfolded protein response (UPR), which is accompanied by increased ER stress. Calcium release from ER together with the increase of intracellular calcium ions in the close vicinity of mitochondria activates executive enzymes (e.g., caspase 12) and the process of apoptosis. The increased intracellular concentration of calcium ions leads to increased production of ROS, which contributes to cell stress. In general, this process leads to the accumulation of calcium ions in mitochondria mainly through mitochondrial uniporter (MCU). This together with increased amounts of ROS, Bax/Bak, members of the Bcl-2 family, and regulators of the intrinsic pathway of apoptosis, contribute to permeabilization of outer mitochondrial membrane, the release of cytochrome $c$, and apoptosis. Calcineurin is calcium and calmodulin-dependent serine/threonine protein phosphatase, which contributes to the activation of caspases and apoptosis. Accumulation of calcium ions in mitochondria together with increased amounts of ROS contributes to the changes in the permeability of mitochondrial permeability transition pore (mPTP), which leads to loss of mitochondrial membrane potential, ATP depletion, and necrosis. Intracellular calcium ions regulate calcium-dependent transcription factors that regulate the expression of genes involved in cell deaths including autophagy. Also, inhibition of IP ${ }_{3}$ Rs or SERCA (which results in depletion of ER stores) can participate in autophagy. PMCA cooperates in the regulation of intracellular calcium. However, a decrease in the production of ATP leads to a decrease in its activity and further accumulation of calcium.

site of the ER called omegasome, recruitment of PI3P effector proteins WD repeat domain phosphoinositide-interacting proteins (WIPI) and zinc-finger FYVE domain-containing protein 1 to the omegasome. By the use of specific inhibitors of CaMKs, it has been shown that CaMKI, which is activated via the calcium/calmodulin system, contributes to the stimulation of WIPI1. This knowledge indicates involvement of $\mathrm{Ca}^{2+}$-dependent signaling, including CaMKI independent of AMP-activated protein kinase, in the process of autophagy [43]. WIPI1 is known to be localized in autophagic membranes and specifically acts in the formation and fission of tubulo-vesicular endosomal transport carriers [44]. In the next step, WIPI2 binds ATG16L1, so, it enables the recruitment of the ATG12-ATG5-ATG16L1 complex. This complex subsequently enhances the ATG3-mediated conjugation of the ATG8 family proteins (ATG8s). These proteins include microtubule-associated protein light chain 3 (LC3) proteins and $\gamma$-aminobutyric acid receptor-associated proteins. They bind to membrane-resident phosphatidylethanolamine (PE) and form the membrane-bound, lipidated form. Lysosomal damage triggers the LC3 recruitment on lysosomes, where lipidated LC3 interacts with the lysosomal calcium channel TRPML1, thus facilitating calcium efflux [45]. TRPML1, also known as mucolipin 1, is the first member of the TRP family of ion channels, which was found to function in the lower portions of the endocytic pathway [46, 47]. TRPML1 is a ubiquitously expressed cation channel found on lysosomes and late endosomes. TRPML1 serves as a key $\mathrm{Ca}^{2+}$ release channel in the lysosomal membrane; in addition, TRPML1 deficiency is closely associated with autophagosome accumulation. TRPML1-mediated lysosomal $\mathrm{Ca}^{2+}$ release activates calcineurin, promotes nuclear translocation, and activation of transcription factor EB (TFEB) that is normally phosphorylated and inhibited by the mammalian target of rapamycin 
complex 1 (mTORC1), a master autophagy suppressor associated with lysosomes [48]. Autophagy-related protein 8 (ATG8), a ubiquitin-like protein required for the formation of autophagosomal membranes, is crucial in the final processes of autophagy, e.g., elongation and closure of autophagosomes [49]. LC3 is involved in the sequestration of specifically labeled cargo into autophagosomes via LIR-containing cargo receptors and docking of specific cargos and adaptor proteins. Sealing of the autophagosomal membrane gives rise to a double-layered vesicle autophagosome, which matures and finally fuses with the lysosome. Acidic hydrolases in the lysosome degrade the autophagic cargo, and salvaged nutrients are released back to the cytoplasm to be used again by the cell [50].

\section{Necrosis and necroptosis and regulation by calcium transport}

Historically, necrosis was considered an accidental cell death caused by physical or chemical interventions. Necrosis is characterized by a rapid loss of energy followed by uncontrolled cell degradation, including disintegration of the plasma membrane with pro-inflammatory consequences [3]. Necroptosis, a special type of cell death is triggered by a series of death receptors such as tumor necrosis factor receptor 1 (TNFR1), TNFR2, and Fas (for review see [5]). The morphology of cell undergoing necroptosis is similar to that of necrosis. Prominent features include cell swelling, nuclear condensation, organelle swelling (mitochondria), loss of plasma membrane integrity, and translucent cytoplasm [51]. This type of cell death is activated, when apoptosis is inhibited. In contrast to apoptosis, necroptosis is considered to be a cytolytic, and thus proinflammatory type of cell death. Necroptosis is activated by a unique caspase-independent signaling pathway, where receptor-interacting serine/threonine protein kinase 1 (RIPK1), RIPK3, and mixed lineage kinase domain-like protein (MLKL) are mainly depending on involved. In some types of cancer (e.g., breast cancer, colorectal cancer), downregulation of RIPK3 or MLKL is related to poor prognosis [52]. However, in other types of cancer (glioblastoma, lung cancer) upregulation of RIPK1 was reported to be responsible for a worse prognosis $[53,54]$.

Regulation of necroptosis by calcium depends on the type of tumor and treatment. Nevertheless, increased levels of cytosolic calcium can be involved also in the process of necroptosis. In glioblastoma, an increase in the cytosolic calcium upregulates necroptosis (Figure 2) induced by the hemagglutinating virus of Japan-envelope. This process is followed by calmodulin-kinase phosphorylation, which activates RIP1/dependent necroptosis [55]. Mitochondrial calcium handling was also reported to be involved in necroptosis [56].

Extremely low-frequency magnetic fields that have antineoplastic activity, trigger necroptosis through elevated intracellular calcium and reactive oxygen species (ROS) levels, and calcium chloride could enhance necroptosis [57]. The reciprocal interaction between calcium-modulated ROS production and ROS-modulated calcium signaling underlies the concept of ROS and $\mathrm{Ca}^{2+}$ crosstalk [11]. Necroptosis after the exposure to extremely low-frequency magnetic fields was further confirmed by the observation of a meaningful increase in phosphorylation of RIPK1, RIPK3, and MLKL proteins.

\section{Ferroptosis and regulation by calcium transporters}

Ferroptosis is a novel type of cell death characterized by the oxidation within the lipid compartment, occurring in physiological conditions and also in some diseases, e.g., cancer. It is an iron-dependent and reactive oxygen species (ROS)-reliant cell death characterized mainly by cytological changes, including decreased or vanished mitochondria cristae, ruptured outer mitochondrial membrane, and a condensed mitochondrial membrane (for review see [58]). Ferroptosis reduces glutathione (GSH) and inhibits glutathione peroxidase 4 (GPX4). Loss of GPX4 activity and deprivation of GSH both lead to lipoxygenase activation in a process closely linked to inflammation. Thus, the authors [58] suggested that ferroptosis might be considered a viable therapeutic strategy to reverse therapy resistance in cancer. Lipoxygenases oxidize polyunsaturated fatty acids to generate metabolites, which additionally promote calcium influx for the final, catastrophic phase of cell death [59]. The intracellular role of $\mathrm{Ca}^{2+}$ in ferroptosis is obscure, in particular its role in regulating phospholipids. Nevertheless, recently it was shown that protein MS4A15, which is localized on the endoplasmic reticulum, constitutively depletes $\mathrm{Ca}^{2+}$ stores and is an independent contributor to ferroptosis resistance. Overexpression of MS4A15 profoundly altered $\mathrm{Ca}^{2+}$ homeostasis and depressed $\mathrm{IP}_{3} \mathrm{R} 1$ expression, resulting in an extensive lipid remodeling [60].

Calcium ions were also shown to be involved in the ferroptosis induction by novel ferroptosis inducer erianin [61]. Erianin (dibenzyl compound) has the potential to induce cell death and inhibit metastasis in lung cancer cells. Activation of the $\mathrm{Ca}^{2+} /$ calmodulin signaling pathway probably caused erianin triggered ferroptosis in lung cancer cells, probably through ROS accumulation and elevated $\mathrm{Fe}^{2+}$ levels.

\section{Mitophagy and regulation by calcium transporters}

Mitochondria are crucial organelles that regulate cell energy metabolism and homeostasis via the ability to produce ATP in respiration. In addition, they synthesize fatty acids, amino acids, and heme. They are crucial in the processes of cell death too. The elimination of mitochondria (both damaged or "physiological" in some types of cells, e.g., erythrocytes or sperm cells) occurs via a process related to autophagy, mitophagy. Mitochondrial dysfunction is associated with several chronic diseases, including cancer $[62,63]$. 
Mitophagy regulates mitochondrial turnover. Two major mechanisms target them for mitophagy. PTEN-induced kinase 1 (PINK1)/Parkin RBR E3 ubiquitin-protein ligase (PARKIN) controls the quality of mitochondria, respectively damaged mitochondria, and targets them for degradation. PINK1 is accumulated as a response to the reduction of mitochondrial potential due to mitochondrial damage in the outer mitochondrial membrane and causes recruitment of PARKIN from the cytosol to the outer mitochondrial membrane (Figure 3). Its E3 ubiquitin-ligase activity promotes mitophagy through ubiquitination of mitochondrial proteins, leading to mitochondrial degradation [64]. Calcium ions play an important role in modulating and/ or triggering mitophagy [65]. Mitochondrial membrane potential represents a very potent force for $\mathrm{Ca}^{2+}$ accumulation in mitochondria via mitochondrial calcium uniporter (MCU). MCU is a $\mathrm{Ca}^{2+}$ channel in the inner mitochondrial membrane and transports cytoplasmic $\mathrm{Ca}^{2+}$ into the mitochondrial matrix, using the large negative membrane potential of the inner mitochondrial membrane as the driving force [66]. Elevated levels of mitochondrial calcium ions increase mitochondrial permeability transition pore (mPTP) opening. mPTP opening seems to be crucial to enhance mitophagy, recruitment of PINK1 depends on mPTP activation (Figure 3) [67]. Loss of PINK1 leads to oxidative stress, oxidative stress, in turn, causes opening of mPTP [68]. It has been shown that PINK1 affects calcium homeostasis in mitochondria; its loss reduces the activity of the mitochondrial $\mathrm{Na}^{+} / \mathrm{Ca}^{2+}$ exchanger, which leads to an accumulation (overload) of $\mathrm{Ca}^{2+}$ in mitochondria and opening of mPTP [69]. PINK1 deficient cells are not able to extrude cytosolic calcium ions by SERCA and/or plasma membrane $\mathrm{Ca}^{2+}$-ATPase (PMCA) because of the impaired ATP generation in mitochondria, so, PINK1 may affect the availability of cytosolic $\mathrm{Ca}^{2+}$ for further handling via mitochondria and endoplasmic reticulum [70]. PINK1 also directly interacts and phosphorylates LETM1, mitochondrial inner membrane protein-mitochondrial proton/ calcium antiporter that mediates proton-dependent calcium efflux from mitochondria [71]. Phosphorylated LETM1 increases calcium release in artificial liposomes and facilitates calcium transport in intact mitochondria [72]. Thus, LETM1 mediates mitochondrial $\mathrm{Ca}^{2+}$ uptake and extrusion in a gradient-dependent manner. In conclusion, loss of PINK1 causes selective increases in MPTP opening and mitochondrial calcium, processes that lead towards the elimination of mitochondria, mitophagy [73]. The second mechanism of mitophagy includes the involvement of receptors in the outer mitochondrial membrane - NIX1, BNIP3, and FUNDC1. They contain sequences that bind LC3/

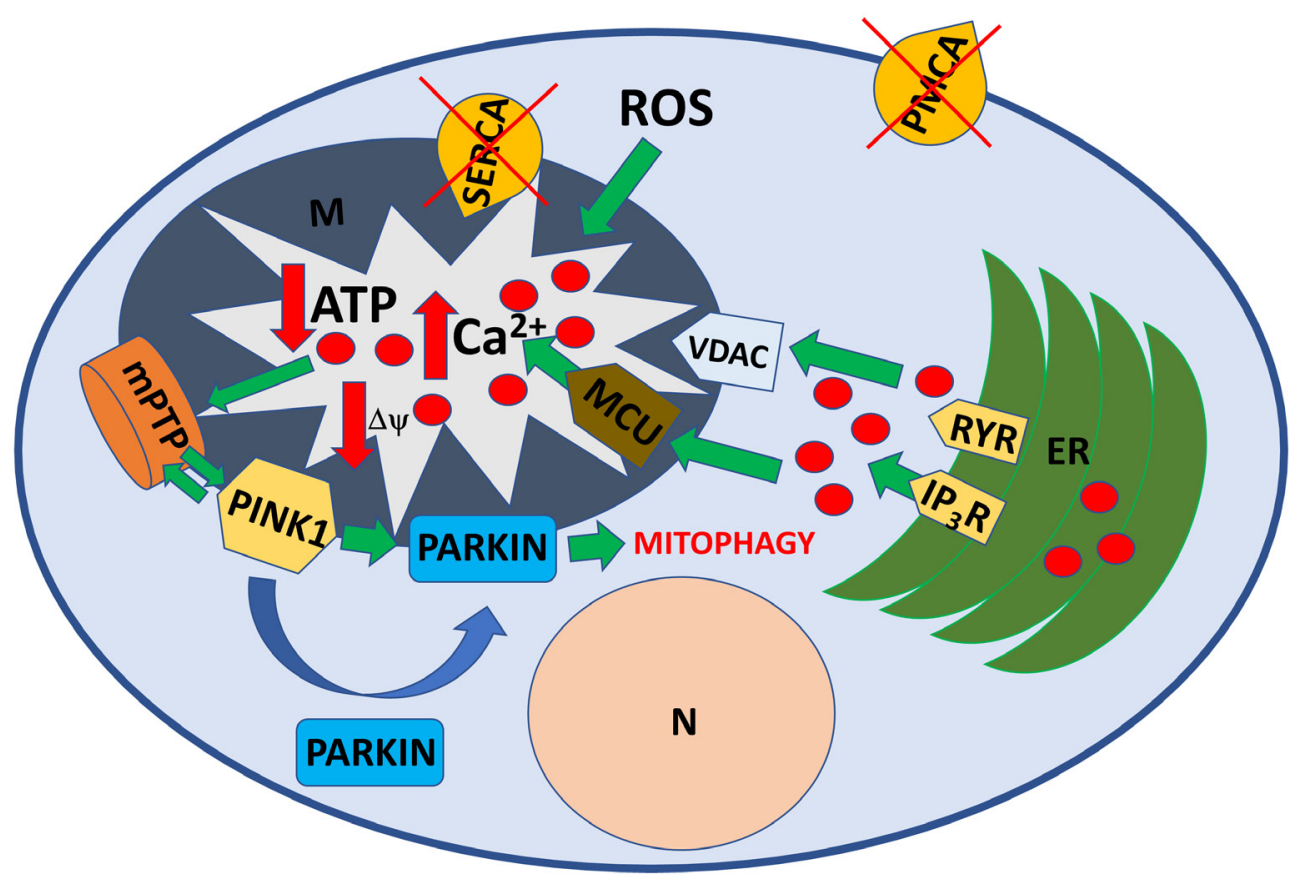

Figure 3. Stimuli associated with a further increase of intracellular reactive oxygen species (ROS) contribute to a release of calcium ions from the endoplasmic reticulum via inositol 1,4,5-trisphosphate receptors $\left(I_{3} R\right)$. ROS potentiate the entry of calcium ions into mitochondria via voltage-dependent anion channel (VDAC) and mitochondrial uniporter (MCU), respectively. This leads to a decrease in mitochondrial potential and depletion of ATP synthesis. Calcium overload in mitochondria is connected with changes of permeability of mitochondrial permeability transition pore (mPTP), accumulation of PTEN-induced kinase 1 (PINK1) in the outer mitochondrial membrane, and recruitment of PARKIN that is necessary for the association of mitochondria with phagophore and mitophagy. Depletion of ATP contributes to the increase in the concentration of intracellular calcium via APTdependent transport systems sarco/endoplasmic reticulum ATPase (SERCA) and plasma membrane calcium ATPase (PMCA). 
GABARAP leading to the degradation of mitochondria. The second mechanism is activated mainly as a response to hypoxia. BNIP3 initiates the opening of the mitochondrial permeability transition pore and cell death in the absence of caspase activation in the environment of hypoxia and acidosis, which leads to cytoplasmic $\mathrm{Ca}^{2+}$ overload that is buffered by sequestration into both the mitochondria and sarcoplasmic reticulum [74]. It is evident that BNIP3 alters endoplasmic reticulum and mitochondrial calcium levels [74]. FUNDC1 plays a critical role in MAMs formation and mitochondrial $\mathrm{Ca}^{2+}$ homeostasis [52]. BNIP3/FUNDC1 mediated accumulation of $\mathrm{Ca}^{2+}$ then induces accumulation of PINK1 and promotes mitophagy activity [75].

In summary, calcium is indisputably involved in different types of programmed cell death. Interestingly, some of the calcium transport systems could be involved in several types of cell death, e.g., modulation of calcium transport through $\mathrm{IP}_{3}$ Rs plays a special role in apoptosis and also in autophagy or necrosis. Although the major regulators of $\mathrm{IP}_{3} \mathrm{Rs}$ are $\mathrm{IP}_{3}$ and $\mathrm{Ca}^{2+}$, their activation is also modulated by various other stimuli (for review see [76]) that may predetermine, which type of cell death will be preferred in cancer cells. A massive release of calcium through $\mathrm{IP}_{3}$ Rs can induce apoptosis, while inhibition of $\mathrm{Ca}^{2+}$ transfer to mitochondria might provide an opportunity to selectively kill cancer cells by necrosis [77].

Although apoptosis is the main type of cell death in the majority of chemotherapeutics, the resistance of cancer cells to apoptosis is the main problem in the treatment of many tumors [78]. Induction of other types of cell death may provide a new approach to anti-tumor therapies. Besides types of cell deaths depicted in this review, some more cell deaths (pyroptosis, oncosis, netosis, entosis, etc.) were described. Although some of them (e.g., pyroptosis) can influence the proliferation, invasion, and metastasis formation [8], little is known about their possible regulation by calcium in cancer cells. Nevertheless, calcium signaling is deeply involved not only in cell deaths but also in cancer development and progression [12], therefore modulation of calcium transport can provide a compelling strategy to develop new treatments of cancer diseases.

Acknowledgments: The work of PB is supported by the Ministry of Health of the Czech Republic, grant NU21-09-00541. All rights reserved. The work of OK is supported by grants APVV-20-0176 and VEGA 2/0040/22.

\section{References}

[1] STRASSER A, VAUX DL. Cell Death in the Origin and Treatment of Cancer. Mol Cell 2020; 78: 1045-1054. https:// doi.org/10.1016/j.molcel.2020.05.014

[2] THOMLISON RH, GRAY LH. The histological structure of some human lung cancers and the possible implications for radiotherapy. Br J Cancer 1955; 9: 539-549.
[3] BORTNER CD, CIDLOWSKI JA. Ion channels and apoptosis in cancer. Philos Trans R Soc Lond B Biol Sci 2014; 369: 20130104. https://doi.org/10.1111/cpr.13154

[4] OUYANG L, SHI Z, ZHAO S, WANG FT, ZHOU TT et al. Programmed cell death pathways in cancer: a review of apoptosis, autophagy and programmed necrosis. Cell Prolif 2012; 45: 487-498. https://doi.org/10.1111/j.13652184.2012.00845.x

[5] LIU X, XIE X, REN Y, SHAO Z, ZHANG N et al. The role of necroptosis in disease and treatment. MedComm 2021; 2 : 730-755. https://doi.org/10.1002/mco2.108

[6] DIKIC I, ELAZAR Z. Mechanism and medical implications of mammalian autophagy. Nat. Rev. Mol. Cell Biol. 2018; 19: 349-364. https://doi.org/10.1038/s41580-018-0003-4

[7] DIXON SJ, LEMBERG KM, LAMPRECHT MR, SKOUTA R, ZAITSEV EM et al. Ferroptosis: an iron-dependent form of nonapoptotic cell death. Cell 2012; 149: 1060-1072. https:// doi.org/10.1016/j.cell.2012.03.042

[8] FANG Y, TIAN S, PAN Y, LI W, WANG Q et al. Pyroptosis: A new frontier in cancer. Biomed Pharmacother 2020; 121: 109595. https://doi.org/10.1016/j.biopha.2019.109595

[9] VARGHESE E, SAMUEL SM, SADIQ Z, KUBATKA P, LISKOVA A et al. Anti-Cancer Agents in Proliferation and Cell Death: The Calcium Connection; Int J Mol Sci 2019; 20: 3017. https://doi.org/10.3390/ijms20123017

[10] ZHAI K, LISKOVA A, KUBATKA P, BUSSELBERG D. Calcium Entry through TRPV1: A Potential Target for the Regulation of Proliferation and Apoptosis in Cancerous and Healthy Cells. Int J Mol Sci 2020; 21: 4177. https://doi. org/10.3390/ijms21114177

[11] GÖRLACH A, BERTRAM K, HUDECOVA S, KRIZANOVA O. Calcium and ROS: A mutual interplay. Redox Biol 2015; 6: 260-271. https://doi.org/10.1016/j.redox.2015.08.010

[12] PATERGNANI S, DANESE A, BOUHAMIDA E, AGUIARI G, PREVIATI $M$ et al. Various Aspects of Calcium Signaling in the Regulation of Apoptosis, Autophagy, Cell Proliferation, and Cancer. Int J Mol Sci 2020; 21: 8323. https://doi. org/10.3390/ijms21218323

[13] LISKOVA V, HUDECOVA S, LENCESOVA L, IULIANO F, SIROVA $\mathrm{M}$ et al. Type 1 Sodium Calcium Exchanger Forms a Complex with Carbonic Anhydrase IX and Via Reverse Mode Activity Contributes to $\mathrm{pH}$ Control in Hypoxic Tumors. Cancers (Basel) 2019; 11: 1139. https://doi. org/10.3390/cancers11081139

[14] HANSON CJ, BOOTMAN MD, RODERICK HL. Cell signalling: IP3 receptors channel calcium into cell death. Curr Biol 2004; 14: R933-R935. https://doi.org/10.1016/j. cub.2004.10.019

[15] HUDECOVA S, MARKOVA J, SIMKO V, CSADEROVA L, STRACINA T et al. Sulforaphane-induced apoptosis involves the type 1 IP3 receptor. Oncotarget 2016; 7: 61403-61418. https://doi.org/10.18632/oncotarget.8968

[16] KOPACEK J, ONDRIAS K, SEDLAKOVA B, TOMASKOVA J, ZAHRADNIKOVA L et al. Type 2 IP(3) receptors are involved in uranyl acetate induced apoptosis in HEK 293 cells. Toxicology 2009; 262: 73-79. https://doi.org/10.1016/j. tox.2009.05.006 
[17] ARBABIAN A, BROULAND JP, GELEBART P, KOVACS T, BOBE R et al. Endoplasmic reticulum calcium pumps and cancer. Biofactors 2011; 37: 139-149. https://doi. org/10.1002/biof.142

[18] KRIZANOVA O, MARKOVA J, PACAK K, SKULTETY L, SOLTYSOVA A et al. Triptolide induces apoptosis through the SERCA 3 upregulation in PC12 cells. Gen Physiol Biophys 2014; 33: 137-144. https://doi.org/10.4149/gpb_2014004

[19] PREVARSKAYA N, ZHANG L, BARRITT G. TRP channels in cancer. Biochim Biophys Acta 2007; 1772: 937-946. https://doi.org/10.1016/j.bbadis.2007.05.006

[20] GALLUZZI L, VITALE I, AARONSON SA, ABRAMS JM, ADAM D et al. Molecular mechanisms of cell death: recommendations of the Nomenclature Committee on Cell Death 2018. Cell Death Differ 2018; 25: 486-541. https://doi. org/10.1038/s41418-017-0012-4

[21] NAGATA S. Apoptosis and Clearance of Apoptotic Cells. Annu Rev Immunol 2018; 36: 489-517. https://doi. org/10.1146/annurev-immunol-042617-053010

[22] THOMBERRY NA, LAXEBNIK Y. Caspases: enemies within. Science 1998; 281: 1312-1316. https://doi.org/10.1126/ science.281.5381.1312

[23] KROEMER G, GALLUZZI L, BRENNER C. Mitochondrial membrane permeabilization in cell death. Physiol Rev 2007; 87: 99-163. https://doi.org/10.1152/physrev.00013.2006

[24] PINTON P, FERRARI D, RAPIZZI E, DI VIRGILIO F, POZZAN $\mathrm{T}$ et al. The $\mathrm{Ca} 2+$ concentration of the endoplasmic reticulum is a key determinant of ceramide-induced apoptosis: significance for the molecular mechanism of Bcl-2 action. EMBO J 2001; 20: 2690-2701. https://doi.org/10.1093/emboj/20.11.2690

[25] ASSEFA Z, BULTYNCK G, SZLUFCIK K, NADIF KASRI $\mathrm{N}$, VERMASSEN E et al. Caspase-3-induced truncation of type 1 inositol trisphosphate receptor accelerates apoptotic cell death and induces inositol trisphosphate-independent calcium release during apoptosis. J Biol Chem 2004; 279: 43227-43236. https://doi.org/10.1002/biof.142

[26] AKL H, MONACO G, LA ROVERE R, WELKENHUYZEN $\mathrm{K}$, KIVILUOTO $\mathrm{S}$ et al. IP3R2 levels dictate the apoptotic sensitivity of diffuse large B-cell lymphoma cells to an IP3R-derived peptide targeting the BH4 domain of Bcl-2. Cell Death Dis 2013; 4: e632. https://doi.org/10.1038/cddis. 2013.140

[27] LENCESOVA L, HUDECOVA S, CSADEROVA L, MARKOVA J, SOLTYSOVA A et al. Sulphide signalling potentiates apoptosis through the up-regulation of IP3 receptor types 1 and 2. Acta Physiol (Oxf) 2013; 208: 350-361. https:// doi.org/10.1111/apha.12105

[28] REZUCHOVA I, HUDECOVA S, SOLTYSOVA A, MATUSKOVA M, DURINIKOVA E et al. Type 3 inositol 1,4,5-trisphosphate receptor has antiapoptotic and proliferative role in cancer cells. Cell Death Dis 2019; 10: 186. https://doi. org/10.1038/s41419-019-1433-4

[29] DOS SANTOS ML, FRANÇA A, LIMA FILHO ACM, FLORENTINO RM, DINIZ PH et al. Inositol 1,4,5-trisphosphate receptor type 3 is involved in resistance to apoptosis and maintenance of human hepatocellular carcinoma. Oncol Lett 2022; 23: 32. https://doi.org/10.3892/ol.2021.13150
[30] CHAMI M, GOZUACIK D, LAGORCE D, BRINI M, FALSON $P$ et al. SERCA1 truncated proteins unable to pump calcium reduce the endoplasmic reticulum calcium concentration and induce apoptosis. J Cell Biol 2001; 153: 1301-1314. https://doi.org/10.1083/jcb.153.6.1301

[31] ANDERSON KJ, CORMIER RT, SCOTT PM. Role of ion channels in gastrointestinal cancer. World J Gastroenterol 2019; 25: 5732-5772. https://doi.org/10.3748/wjg.v25. i3 38.5732

[32] SHUBA YM. Ca2+ channel-forming ORAI proteins: cancer foes or cancer allies? Exp Oncol. 2019; 41: 200-206. https://doi.org/10.32471/exp-oncology.2312-8852.vol-41no- 3.13473

[33] DENTON D, KUMAR S. Autophagy-dependent cell death. Cell Death Differ 2019; 26: 605-616. https://doi.org/10.1038/ s41418-018-0252-y

[34] LEE YH, KIM J, PARK K, LEE MS. $\beta$-cell autophagy: Mechanism and role in $\beta$-cell dysfunction. Mol Metab 2019; 27: S92-S103. https://doi.org/10.1016/j.molmet.2019.06.014

[35] IKARI S, LU SL, HAO F, IMAI K, ARAKI Y et al. Starvationinduced autophagy via calcium-dependent TFEB dephosphorylation is suppressed by Shigyakusan. Plos One 2020; 15: e0230156. https://doi.org/10.1371/journal.pone.0230156

[36] ZHANG L, ZHANG Y, JIANG Y, DOU X, LI S et al. Upregulated SOCC and IP3R calcium channels and subsequent elevated cytoplasmic calcium signaling promote nonalcoholic fatty liver disease by inhibiting autophagy. Mol Cell Biochem 2021; 476: 3163-3175. https://doi.org/10.1007/s11010-02104150-0

[37] QI ZH, CHEN LX. Endoplasmic Reticulum Stress and Autophagy. Adv Exp Med Biol 2019; 1206: 167-177. https://doi. org/10.1007/978-981-15-0602-4_8

[38] YORIMITSU T, NAIR U, YANG ZF, KLIONSKY DJ. Endoplasmic reticulum stress triggers autophagy. J Biol Chem 2006; 281: 30299-30304. https://doi.org/10.1074/jbc. M607007200

[39] CREAMER TP. Calcineurin. Cell Commun Signal 2020; 18: 137. https://doi.org/10.1186/s12964-020-00636-4

[40] CHENG ZY. The FoxO-Autophagy Axis in Health and Disease. Trends Endocrinol Metab 2019; 30: 658-671. https:// doi.org/10.1016/j.tem.2019.07.009

[41] JUNHO CVC, CAIO-SILVA W, TRENTIN-SONODA M, CARNEIRO-RAMOS MS. An Overview of the Role of Calcium/Calmodulin-Dependent Protein Kinase in Cardiorenal Syndrome. Front Physiol 2020; 11: 735. https://doi. org/10.3389/fphys.2020.00735

[42] LI X, WU XQ, DENG R, LI DD, TANG J et al. CaMKIImediated Beclin 1 phosphorylation regulates autophagy that promotes degradation of Id and neuroblastoma cell differentiation. Nat Commun 2017; 8: 1159. https://doi.org/10.1038/ s41467-017-01272-2

[43] PFISTERER SG, MAUTHE M, CODOGNO P, PROIKAS-CEZANNE T. Ca2+/Calmodulin-Dependent Kinase (CaMK) Signaling via CaMKI and AMP-Activated Protein Kinase Contributes to the Regulation of WIPI-1 at the Onset of Autophagy. Mol Pharmacol 2011; 80: 1066-1075. https:// doi.org/10.1124/mol.111.071761 
[44] DE LEO MG, BERGER P, MAYER A. WIPI1 promotes fission of endosomal transport carriers and formation of autophagosomes through distinct mechanisms. Autophagy 2021; 17: 3644-3670. https://doi.org/10.1080/15548627.202 1.1886830

[45] NAKAMURA S, SHIGEYAMA S, MINAMI S, SHIMA T, AKAYAMA $S$ et al. LC3 lipidation is essential for TFEB activation during the lysosomal damage response to kidney injury. Nat Cell Biol 2020; 22: 1252-1263. https://doi. org/10.1038/s41556-020-00583-9

[46] COLLETTI GA, KISELYOV K. TRPML1. Adv Exp Med Biol 2011; 704: 209-219. https://doi.org/10.1007/978-94-0070265-3_11

[47] CHENG XP, SHEN DB, SAMIE M, XU HX. Mucolipins: Intracellular TRPML1-3 channels. FEBS Lett 2010; 584: 20132021. https://doi.org/10.1016/j.febslet.2009.12.056

[48] HUANG P, XU MN, WU Y, SYEDA AKR, DONG XP. Multiple facets of TRPML1 in autophagy. Cell Calcium 2020; 88: 102196. https://doi.org/10.1016/j.ceca.2020.102196

[49] SHPILKA T, WEIDBERG H, PIETROKOVSKI S, ELAZAR Z. Atg8: an autophagy-related ubiquitin-like protein family. Genome Biol 2011; 12: 226. https://doi.org/10.1186/gb2011-12-7-226

[50] LI L, TONG M, FU Y, CHEN F, ZHANG S et al. Lipids and membrane-associated proteins in autophagy. Protein Cell 2021; 12: 520-544. https://doi.org/10.1007/s13238-02000793-9

[51] ZHANG Y, CHEN X, GUEYDAN C, HAN J. Plasma membrane changes during programmed cell deaths. Cell Res 2018; 28: 9-21. https://doi.org/10.1038/cr.2017.133

[52] LIU L, LI YM, CHEN Q. The Emerging Role of FUNDC1-Mediated Mitophagy in Cardiovascular Diseases. Front Physiol 2021; 12: 807654. https://doi.org/10.3389/fphys.2021.807654

[53] PARK S, HATANPAA KJ, XIE Y, MICKEY BE, MADDENET $\mathrm{CJ}$ et al. The receptor interacting protein 1 inhibits p53 induction through NF-kappaB activation and confers a worse prognosis in glioblastoma. Cancer Res 2009; 69: 2809-2816. https://doi.org/10.1158/0008-5472.CAN-08-4079

[54] MONTALBAN-BRAVO G, CLASS CA, GANAN-GOMEZ I, KANAGAL-SHAMANNA R, SASAKI K et al. Transcriptomic analysis implicates necroptosis in disease progression and prognosis in myelodysplastic syndromes. Leukemia 2020; 34: 872-881. https://doi.org/10.1038/s41375-019-0623-5

[55] NOMURA M, UENO A, SAGA K, FUKUZAWA M, KANEDA Y. Accumulation of cytosolic calcium induces necroptotic cell death in human neuroblastoma. Cancer Res 2014; 74: 1056-1066. https://doi.org/10.1158/0008-5472.CAN-13-1283

[56] FAIZAN MI, AHMAD T. Altered mitochondrial calcium handling and cell death by necroptosis: An emerging paradigm. Mitochondrion 2021; 57: 47-62. https://doi. org/10.1016/j.mito.2020.12.004

[57] BARATI M, JAVIDI MA, DARVISHI B, SHARIATPANAHI SP, MESBAH MOOSAVI ZS et al. Necroptosis triggered by ROS accumulation and $\mathrm{Ca}(2+)$ overload, partly explains the inflammatory responses and anti-cancer effects associated with $1 \mathrm{~Hz}, 100 \mathrm{mT}$ ELF-MF in vivo. Free Radic Biol Med 2021; 169: 84-98. https://doi.org/10.1111/cpr.13154
[58] MOU Y, WANG J, WU J, HE D, ZHANG CH et al. Ferroptosis, a new form of cell death: opportunities and challenges in cancer. J Hematol Oncol 2019; 12: 34. https://doi. org/10.1186/s13045-019-0720-y

[59] LEWERENZ J, HEWETT SJ, HUANG Y, LAMBROS M, GOUT PW et al. The cystine/glutamate antiporter system $\mathrm{x}(\mathrm{c})(-)$ in health and disease: from molecular mechanisms to novel therapeutic opportunities. Antioxid Redox Signal 2013; 18: 522-555. https://doi.org/10.1089/ars.2011.4391

[60] XIN S, MUELLER C, PFEIFFER S, KRAFT VAN, MERLPHAM J et al. MS4A15 drives ferroptosis resistance through calcium-restricted lipid remodeling. Cell Death Differ 2021. [Online ahead of print] https://doi.org/10.1038/s41418-02100883-Z

[61] CHEN P, WU Q, FENG J, YAN L, SUN Y et al. Erianin, a novel dibenzyl compound in Dendrobium extract, inhibits lung cancer cell growth and migration via calcium/calmodulin-dependent ferroptosis. Signal Transduct Target Ther 2020; 5: 51. https://doi.org/10.1038/s41392-020-0149-3

[62] BOLAND ML, CHOURASIA AH, MACLEOD KF. Mitochondrial dysfunction in cancer. Frontiers in Oncology 2013; 3: 292. https://doi.org/10.1111/cpr.13154

[63] NICOLSON GL. Mitochondrial Dysfunction and Chronic Disease: Treatment with natural supplements. Altern Ther Health Med 2014; 20: 18-25.

[64] QUINN PMJ, MOREIRA PI, AMBROSIO AF, ALVES CH. PINK1/PARKIN signalling in neurodegeneration and neuroinflammation. Acta Neuropathol Commun 2020; 8: 189. https://doi.org/10.1186/s40478-020-01062-w

[65] YU SS, ZHENG SF, LENG J, WANG SL, ZHAO T et al. Inhibition of mitochondrial calcium uniporter protects neurocytes from ischemia/reperfusion injury via the inhibition of excessive mitophagy. Neurosci Lett 2016; 628: 24-29. https:// doi.org/10.1016/j.neulet.2016.06.012

[66] VAN KEUREN AM, TSAI CW, BALDERAS E, RODRIGUEZ MX, CHAUDHURI D et al. Mechanisms of EMREDependent MCU Opening in the Mitochondrial Calcium Uniporter Complex. Cell Rep 2020; 33: 108486. https://doi. org/10.1016/j.celrep.2020.108486

[67] ROTTEnberg H, HOEK JB. The Mitochondrial Permeability Transition: Nexus of Aging, Disease and Longevity. Cells 2021; 10: 79. https://doi.org/10.3390/cells10010079

[68] FERNYHOUGH P, CALCUTT NA. Mitochondrial Dysfunction in Neurodegeneration and Peripheral Neuropathies. In: RL. Bell, S. Rahman (Eds.). International review of neurobiology. Elsevier 2019, p. 1-238. ISSN 0074-7742

[69] RIMESSI A, BONORA M, MARCHI S, PATERGNANI S, MAROBBIO CM et al. Perturbed mitochondrial Ca2+ signals as causes or consequences of mitophagy induction. Autophagy 2013; 9: 1677-1686. https://doi.org/10.4161/ auto. 24795

[70] HEEMAN B, VAN DEN HAUTE C, AELVOET SA, VALSECCHI F, RODENBURG RJ et al. Depletion of PINK1 affects mitochondrial metabolism, calcium homeostasis and energy maintenance. J Cell Sci 2011; 124: 1115-1125. https:// doi.org/10.1242/jcs.078303 
[71] JIANG DW, ZHAO LL, CLAPHAM DE. Genome-Wide RNAi Screen Identifies Letm1 as a Mitochondrial $\mathrm{Ca} 2+$ / H+ Antiporter. Science 2009; 326: 144-147. https://doi. org/10.1126/science. 1175145

[72] HUANG E, QU D, HUANG T, RIZZI N, BOONYING W et al. PINK1-mediated phosphorylation of LETM1 regulates mitochondrial calcium transport and protects neurons against mitochondrial stress. Nat Commun 2017; 8: 1399. https://doi.org/10.1038/s41467-017-01435-1

[73] GAUTIER CA, GIAIME E, CABALLERO E, NÚÑEZ L, SONG $\mathrm{Z}$ et al. Regulation of mitochondrial permeability transition pore by PINK1. Mol Neurodegener 2012; 7: 22. https://doi.org/10.1186/1750-1326-7-22

[74] GRAHAM RM, THOMPSON JW, WEBSTER KA. BNIP3 promotes calcium and calpain-dependent cell death. Life Sci 2015; 142: 26-35. https://doi.org/10.1016/j.lfs.2015.10.010
[75] ZHANG T, XUE L, LI L, TANG C, WAN Z et al. BNIP3 Induces Full- length PINK1 Accumulation to Promote Mitophagy. Mol Biol Cell 2014; 25: 21616-21629. https://doi. org/10.1074/jbc.M116.733410

[76] PROLE DL, TAYLOR CW. Structure and Function of IP3 Receptors. Cold Spring Harb Perspect Biol 2019; 11: a035063. https://doi.org/10.1101/cshperspect.a035063

[77] CARDENAS C, MULLER M, MCNEAL A, LOVY A, JANA F et al. Selective vulnerability of cancer cells by inhibition of $\mathrm{Ca} 2+$ transfer from endoplasmic reticulum to mitochondria. Cell Rep 2016; 14: 2313-2324. https://doi.org/10.1016/j.celrep.2016.02.030

[78] COATES JM, GALANTE JM, BOLD RJ. Cancer therapy beyond apoptosis: autophagy and anoikis as mechanisms of cell death. J Surg Res 2010; 164: 301-308. https://doi. org/10.1016/j.jss.2009.07.011 